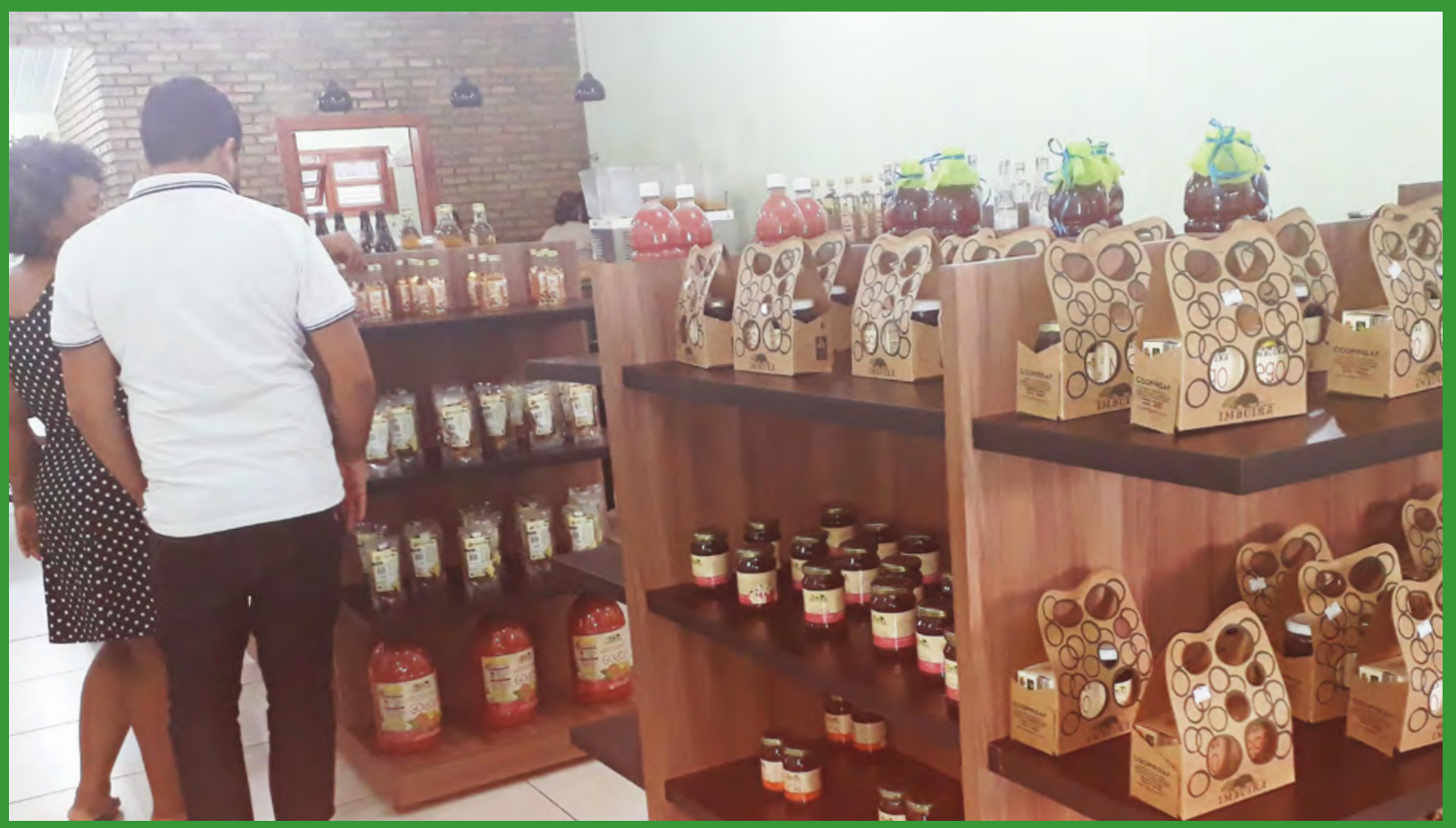

\title{
Mapeamento de associações e cooperativas no território médio Rio de Contas do estado da Bahia
}

\section{Egly Mota Santos ${ }^{1}$}

eglymotta@hotmail.com

\section{João Sotero do Vale Júnior ${ }^{2}$}

joao.sotero.js@gmail.com

1 Acadêmica do Curso de Administração, Universidade do Estado da Bahia - UNEB , Câmpus XXI, Ipiaú-BA

2 Orientador, docente da Universidade do Estado da Bahia - UNEB 
Associativismo e Cooperativismo são alguns dos principais pilares da economia solidária no Brasil. Por este motivo, este relato descreve a experiência no projeto de extensão intitulado "Mapeamento de Associações e Cooperativas no Território Médio Rio de Contas", localizado no Estado da Bahia, que busca mapear essas organizações para posterior construção de material socioeducativo baseado nos dados qualitativos coletados na pesquisa, que sirvam para desenvolver políticas públicas com base no conhecimento científico adquirido e contribuir com o desenvolvimento socioeconômico no território. Observou-se que o projeto promoveu um despertar tanto da gestão pública quanto da comunidade acadêmica para desenvolver e fomentar essas organizações no território.

Palavras-chave: Mapeamento. Associativismo. Cooperativismo. Desenvolvimento Territorial. Economia Solidária.

ABSTRACT

Associativism and cooperativism are some of the main pillars of the solidarity economy in Brazil. For this reason, this report describes the experience in the extension project entitled Mapping of Associations and Cooperatives in the Average River Territory of Accounts, located in the State of Bahia, Brazil, that seeks to map these organizations for later construction of socio-educational material based on the qualitative data collected in the research that serve to develop public policies based on the acquired scientific knowledge and contribute with socioeconomic development in the territory. It was observed that the project promoted an awakening of both public management and the academic community to develop and foster these organizations in the territory.

Keywords: Mapping. Associativism. Cooperativism. Territorial Development. Solidarity Economy.

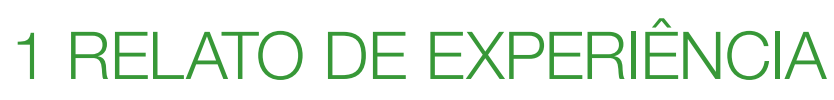

0 Associativismo e o Cooperativismo são ações que promovem crescimento socioeconômico, sustentável e inclusivo no país. Essas ações são formas das pessoas se organizarem em favor de um bem comum, como descreve Amaral (2012), baseado nos princípios de igualdade, solidariedade, ajuda mútua e democracia. Trata-se de um exemplo de gestão compartilhada e inclusiva, que faz parte do leque das organizações de terceiro setor, que visam o bem-estar social e a sustentabilidade das regiões onde se localizam.

Frente às potencialidades do território de identidade Médio Rio de Contas, localizado no Estado da Bahia, onde se encontra extensa riqueza cultural, ambiental e econômica, o fomento a essas atividades pode impulsionar ainda mais o desenvolvimento territorial. Como afirmado por Santos et al. (2015), "0 território, como espaço inventado, reinventado, ou naturalmente erguido por forças afins, e ao mesmo tempo adversas, pode ser potencializado em seus resultados satisfatórios, em se tratando de um paradigma inclinado à cooperação", além de incentivar a economia sustentável e solidária, reunindo pessoas em busca de objetivos comuns e coletivos, voltados à responsabilidade socioeconômica e ambiental.

Com isto, este projeto surgiu como uma alternativa de discussão sobre o papel desenvolvido pelas organizações do terceiro setor dentro do território, pois ainda não há uma compilação desses dados disponibilizados pelo território de identidade em estudo, que permita a promoção de ações para defender e garantir a construção e manutenção desse setor e para capacitar associados e cooperados na prática da economia solidária, como forma de desenvolvimento humano, local e social.

A organização de um empreendimento solidário, ao tirar o indivíduo de seu mundo particular, relacionando-o com os outros, pelos laços sociais da amizade, da emoção, da razão, da associação, da cooperação, construindo espaços coletivos, desperta a responsabilidade sociale a solidariedade, elementos fundamentais ao desenvolvimento do ser humano e de seus espaços de vida. Os seres humanos se humanizam pelo reconhecimento solidário e cooperativo do outro. (FRANTZ, 2012, p. 26)

Para isso, o objetivo deste projeto foi mapear as associações e cooperativas que fazem parte do Território Médio Rio de Contas, buscando construir material educativo informativo que sirva de base para discussões de ações efetivas no desenvolvimento dessas organizações no território.

As informações obtidas, trabalhos produzidos e as discussões a respeito do tema são apresentados anualmente no evento promovido pela equipe do projeto na Universidade do Estado da Bahia (UNEB), intitulado "Colóquio de Associações e Cooperativas do Território Médio Rio de Contas", onde as informações são transmitidas através de palestras, apresentações e mesas redondas com pesquisadores, estudantes, 
instituições bancárias e agentes importantes na área do associativismo e cooperativismo, além de representantes do território, visando despertar a comunidade acadêmica e regional para a importância de fomentar estas ações na sociedade atual.

A metodologia utilizada consistiu em uma pesquisa de caráter qualitativo, identificando o público-alvo e logo após a montagem de formulários que foram aplicados a partir do mês de junho do ano de 2017, nas prefeituras ou secretarias responsáveis dos 16 municípios (Itagi, Boa Nova, Ipiaú, Manoel Vitorino, Jitaúna, Barra do Rocha, Jequié, Itamari, Apuarema, Gongogi, Ubatã, Nova lbiá, Ibirataia, Itagibá, Dário Meira e Aiquara) que compõem o território. A aplicação dos formulários se deu através de contato por meios de comunicação, como telefones fixos e celulares, redes sociais, correio eletrônico, e de visitas a algumas associações e cooperativas da região, inclusive na fundação de uma delas (Figura 1). Por meio destes contatos se buscou obter dados relevantes sobre o seguimento e funcionalidade (ativas, em extinção ou não ativas) destas organizações.

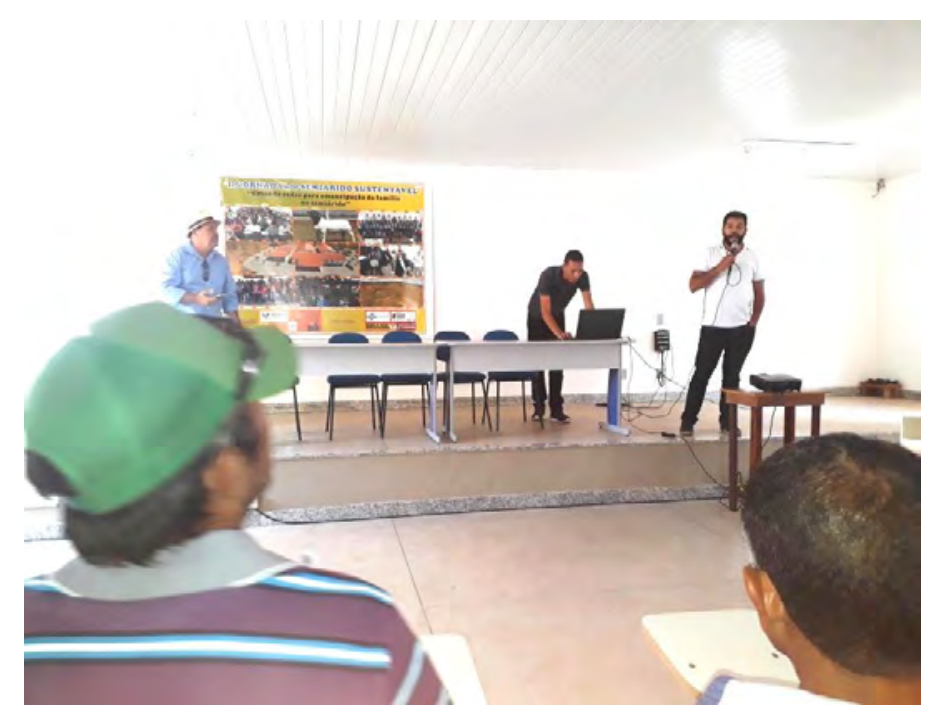

Figura 1: Participação do grupo de pesquisa da UNEB na fundação de uma cooperativa de caprino e ovinocultura no território.

Fonte: Dados desta pesquisa

Em seguida, foi realizada uma pesquisa em sites que continham dados relacionados a essas organizações como nome, CNPJ, localização e o ramo de identificação do qual fazem parte.

Neste contato inicial com as instituições, identificou-se que as prefeituras e órgãos públicos não têm se preocupado com o tema, principalmente devido à escassez de informações durante a pesquisa. Muitos deles sequer haviam se preocupado com o registro dessas associações e cooperativas nos órgãos responsáveis, pois os alunos pesquisadores tiveram dificuldades em obter essas informações com os atuais gestores responsáveis pelo registro desses dados.

Durante a pesquisa foram identificadas e tabuladas 276 associações e apenas 6 cooperativas no Território Médio Rio de Contas, sendo, dentre estas, algumas em processo de extinção e outras que se esforçam ainda com muitas dificuldades para se manterem atuantes.

Uma das visitas realizadas durante a pesquisa deu-se na COOPROAF - Cooperativa de Produção e Comercialização dos produtos da Agricultura Familiar do Sudoeste da Bahia, localizada no município de Manoel Vitorino-BA (Figura 2). 


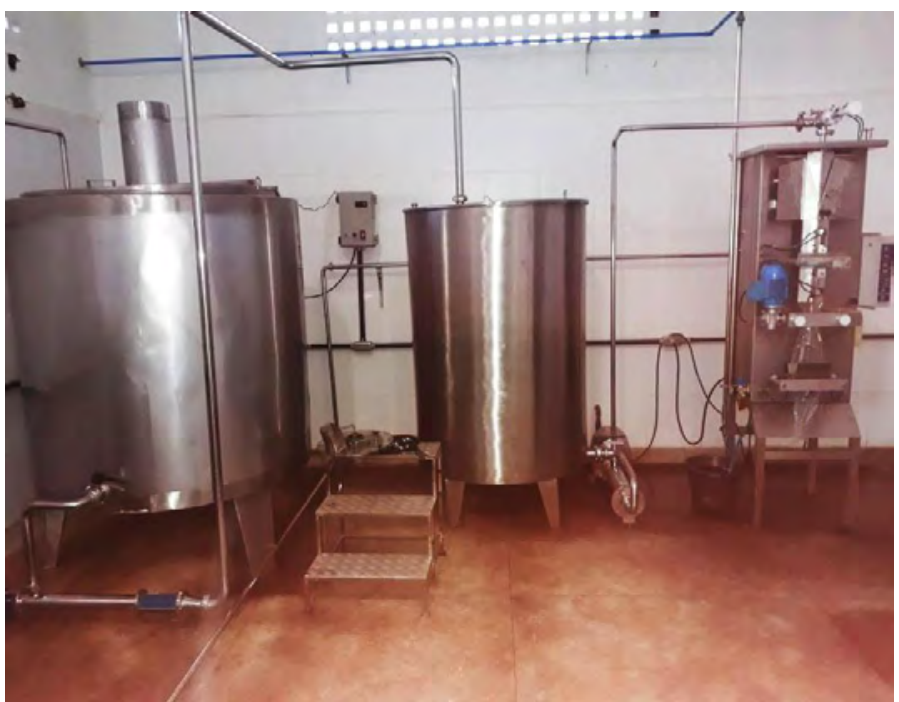

Figura 2: Visita à agroindústria de frutas da COOPROAF, em Manoel Vitorino-BA.

Fonte: Dados desta pesquisa

Durante a visita a algumas cooperativas e associações (Figura 3), os estudantes puderam visualizar o funcionamento e a importância econômica e social dessas organizações para a sociedade, bem como entender a importância do gerenciamento compartilhado desses aglomerados.

A finalização do mapeamento resultouna produção de uma cartilha, constando informações referentes a essas associações e cooperativas, para ser compartilhada com os diversos setores econômicos, sociais e educacionais.

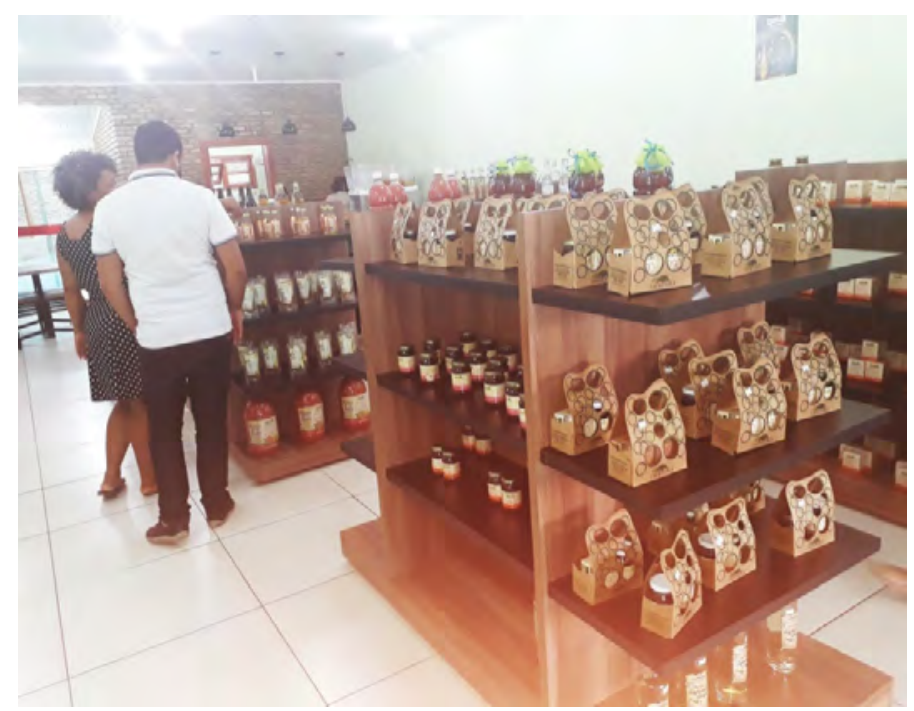

Figura 3: Visita à loja Vitorinas, fornecedora dos produtos Imbuíras, produzido pela COOPROAF em Manoel Vitorino-BA.

Fonte: Dados desta pesquisa

As associações e cooperativas são meios de crescimento socioeconômico e sustentável que ainda precisam muito ser assistidos. Por meio deste trabalho, observou-se o despertamento e a sensibilização dos representantes e integrantes do território para a adoção de medidas que promovam e sustentem esses movimentos.

Os resultados demonstraram o quanto o cooperativismo ainda precisa ganhar força nesse território, pois não há fomento ao desenvolvimento dessas atividades, além de muitas delas não terem o apoio necessário para darem prosseguimento.

Com o desenvolvimento da ciência na área do terceiro setor, acredita-se que esse projeto ainda poderá gerar muitas discussões e reflexões de possíveis alternativas a respeito da importância desses movimentos organizados, demonstrando ser um vasto campo que precisa ser explorado e avaliado com mais precisão 
e aprofundamento, pois estas organizações consistem em importantes fontes de renda e ferramentas na solução de problemas gerados pelo capitalismo mal gerido e distribuído de forma injusta, além de gerar inclusão e sustentabilidade econômica, ambiental e social.

\section{REFERÊNCIAS}

AMARAL, I. G. Associativismo e Cooperativismo. UFERSA. Disponível em: http://www2.ufersa.edu.br/portal/ view/uploads/setores/241/Cartilha\%20de\%20Associativismo\%20e\%20Cooperativismo.PET-PROEX.pdf. Acesso em: 02 jul. 2019.

FRANTZ, W. Associativismo, Cooperativismo e Economia solidária. ljuí: Unijuí, 2012. 168 p. Disponível em: http://bibliodigital.unijui.edu.br:8080/xmlui/bitstream/handle/123456789/963/Associativismo,\%20 cooperativismo\%20e\%20economia\%20solid\%C3\%A1ria.pdf?sequence=1. Acesso em: 03 dez. 2018.

SANTOS, E.L.O.; BAIARDI, A.; SANTOS, E.B. Impacto das Organizações de Cooperação na Bahia: Abordagem pelo Índice de Desenvolvimento Humano. In: Seminário Internacional Dinâmica Territorial e Desenvolvimento Socioambiental: “Terra em Transe”, 7., 2015, Salvador. Anais [...]. Salvador: Ucsal, 2015. p. 1-20. Disponível em: http://noosfero.ucsal.br/articles/0009/2492/impacto-das-organiza-es-de-coopera-o-na-bahia-abordagempelo-ndice-de-desenvolvimento-humano.pdf. Acesso em: 30 jun. 2019. 